\title{
A CONDIÇÃA ESTRUTURA DA HESITAÇÃO: ANÁLISE DO CONTO “EVELINE", DE JAMES JOYCE, SEGUNDO CONCEITOS DE ANTHONY GIDDENS
}

\author{
Daniella Paez Coelho ${ }^{1}$ \\ Vera Lucia Lenz Vianna ${ }^{2}$
}

\begin{abstract}
Resumo: No conto de James Joyce, "Eveline”, da obra Dubliners (1914), desenvolve-se o conflito de uma jovem frente à tomada de uma decisão que lhe pode ditar o destino. Construída predominantemente por fluxo de consciência, a narrativa centra-se no espaço interior da protagonista. A condição de Eveline assemelha-se aos conflitos reais, estudados e diagnosticados pelo sociólogo Anthony Giddens, em sua obra Modernidade e identidade (2002). Aplicando conceitos-chave da obra de Giddens, este trabalho objetivou analisar a protagonista, entendendo sua situação como um exemplo do desafio de como o "projeto reflexivo do eu", a que Giddens chama a constante elaboração da auto-identidade, move, nos indivíduos modernos, sensações de "medo", "ansiedade”, "insegurança”, "isolamento". Sob esta perspectiva, a relação entre ficção e realidade revela-se ainda mais estreita neste conto, em que o realismo descritivo, característica marcante de Joyce, faz de Eveline uma "quase pessoa".
\end{abstract}

Palavras-chave: Joyce; Modernidade; auto-identidade.

Abstract: James Joyce's short story "Eveline", present in his work Dubliners (1914), develops the conflict of a girl facing a decision of her destiny. Structered mainly through stream of consciousness, the narrative centers around the interior space of the protagonist. The condition in which Eveline finds herself resembles real conflicts studied and diagnosed by the sociologist Anthony Giddens in Modernity and Self-Identity (2002). By applying key concepts from Giddens work this essay intended to analyze the protagonist, understanding her situation as an example of the challenge of how the "reflexive project of the self" (the name given by Giddens to the constant elaboration of self-identity) promotes in the modern individuals "fear", "anxiety", "insecurity", "isolation". Under this perspective the relation between fiction and reality reveals itself to be even more closely linked in this short story, in which the descriptive realism, key characteristic of Joyce, makes Eveline almost "like a real person".

Keywords: Joyce; Modernity; self-identity.

1 Mestranda em Estudos Literários pelo PPGL/UFSM. E-mail: daniella.paez.coelho@gmail.com 2 Professora do Departamento de Letras Estrangeiras Modernas da UFSM. E-mail: lenzvl@gmail.com

Literatura e Autoritarismo, Santa Maria, n. 29: Censura e Violência, jan.-jun. 2017, p. 81-96. - ISSN 1679-849X 


\section{INTRODUÇÃO}

Este trabalho tem por objetivo analisar o conto "Eveline", de James Joyce, buscando explicitar, na evolução da narrativa, a forma como se desenvolve a temática do conflito interior da protagonista que lhe dá o título, utilizando categorias propostas pelo sociólogo Anthony Giddens, em sua obra Modernidade e Identidade (2002). O conto centra-se no estado de indecisão de uma jovem prestes a abandonar a família para fugir com o namorado, rompendo, assim, uma relação de parasitismo do qual fora vítima desde a morte da mãe. A composição narrativa foca-se fundamentalmente em seus pensamentos e lembranças, na tessitura de uma ponderação sobre sua vida, em decorrência do impasse em que se encontra. Semelhante situação a das que Giddens discute, ao tratar da complexa construção da "auto-identidade" do indivíduo, sobretudo face às constantes mudanças nos níveis institucionais e sociais.

A obra do sociólogo, embora trate de questões reais, pode nos servir como chave de entendimento para analisar certas relações entre as pessoas fictícias, as "massas de palavras"3 (p.55), como o crítico literário Edward Forster define as personagens. Sobre esse ponto, em seu Aspects of novel (1976), o autor dedica dois capítulos, "People" (I e II), nos quais atribui o estatuto de quase pessoa à personagem, pelo fato de com esta estabelecermos um momentâneo vínculo de intimidade, ao adentrarmos seu mundo ficcional, e partilharmos de sua realidade. Nesse sentido, Forster (1976) afirma que o que nos fascina é o fato de, diferentemente das pessoas reais, uma personagem nos aparecer em geral totalmente acessível; sabemos tudo dela, justamente porque ela é tudo o que nos é dito (p.57).

O conto de Joyce se desenrola predominantemente no universo interior da protagonista Eveline, na iminência de decidir seu futuro, e se configura como um exemplo, embora fictício, dos desafios de um indivíduo frente à possibilidade de mudanças que se lhe apresentam. Considerando Eveline como uma "quase pessoa", na acepção de Forster, buscaremos entender, a partir de uma análise estilística conjugada a conceitos da teoria de Giddens, a protagonista desta Dublin quase real $^{4}$ do início do século XX, como um modelo dos conflitos da Modernidade, levantados e analisados pelo sociólogo.

Para tal, este trabalho está dividido em três momentos: no primeiro, far-se-á uma breve apresentação dos principais conceitos-chave, aqui utilizados, propostos por Giddens; no segundo momento, serão analisados aspectos da obra em que o conto se insere, sua relação com o tempo histórico, bem como elementos estruturais do conto, para proceder, no terceiro momento, à análise da protagonista, segundo conceitos de Giddens.

\footnotetext{
3 No original "word-masses". Para este artigo, traduziremos as expressões em inglês no corpo do texto, colocando as expressões no original ao pé da página, a fim de facilitar a fluidez da leitura.

4 A título de curiosidade, nas "Notes" da edição de Dubliners utilizada para este trabalho, consta que há a possibilidade de Joyce ter escolhido o nome da protagonista com a intenção de uma referência a outra personagem de uma história folclórica, que, por sua vez, pode ter sido inspirada em uma pessoa real. Assim, estabelece-se desde já um jogo entre ficção e realidade (JOYCE, pp.253-254).
} 


\section{O INDIVÍDUO MODERNO CONSTITUINDO-SE FRENTE A INSTITUIÇÕES}

MÓVEIS.

Em sua obra Modernidade e identidade, Anthony Giddens (2002) $)^{5}$ avalia como alguns fenômenos sociais da Modernidade, período regido sob os signos do capitalismo, do dinamismo e da diluição das fronteiras de tempo e espaço (p.9), influenciam na configuração da identidade do indivíduo. De acordo com o autor, frente a um contexto social de constantes variações, o indivíduo depara-se com o desafio de uma igualmente constante (re)adaptação, a qual está sempre a refletir em sua "auto-identidade" (p.12). É nesse complexo processo de organização, resultante da contínua interação entre o exterior e o íntimo, a que o sociólogo chama de "projeto reflexivo do eu" (id., ibid.), que se centra a obra. Giddens entende que a Modernidade se instaurou sobre o "estatuto da dúvida" e configura-se como uma "cultura do risco" (pp. 10-11), em que grandes perigos encontram-se constantemente na iminência de desencadearem acidentes, guerras, tragédias, de âmbito global. Para superar tais riscos, os indivíduos conectam-se, em relações de interdependência, asseguradas pela "confiança", um dos conceitos centrais desta obra, que consiste em uma entrega e compromisso mútuos (pp. 11-13). A "confiança” seria o elemento que equilibraria os dois extremos de que se constrói uma relação: por um lado a proteção, que exige exposição, e por outro o próprio risco de que desta decorre.

O problema central da obra, o "projeto reflexivo do eu”, é desenvolvido apresentando os desafios da estruturação da "auto-identidade" frente à configuração social constantemente mutável, a qual lhe impõe constantes revisões e que se reflete no "estilo de vida" pelo qual optamos para nos apresentarmos ao mundo (pp. 13-16). Estamos, para Giddens, em um constante desafio de "recapacitação", pois as mudanças no cenário moderno, no qual impera a dúvida, provocam não raramente a "perda do sentido pessoal", que o autor entende como o problema fundamental desta época e que pode acarretar em um "isolamento existencial" do indivíduo (pp. 14-16).

"Segurança ontológica" e "ansiedade existencial", dois conceitos igualmente fundamentais na obra, relacionam-se, segundo Giddens, na complexidade dos mecanismos de defesa e ação que são engendrados desde a infância. Ante a realidade, entendida como "um conjunto de experiências constitutivamente organizado pela relação mútua entre a criança e os que cuidam dela" (p. 42), a sensação de "segurança ontológica" é assegurada pela manutenção de um "casulo protetor", i.e., todo um complexo que resulta das experiências do indivíduo e que paulatinamente lhe possibilita reconhecimentos e lhe provê modelos de ação. Ao mesmo tempo, afirma Giddens, o casulo "é essencialmente um sentido de 'irrealidade' [...] um parêntese, no nível da prática, em eventos possíveis que poderiam ameaçar a integridade corporal ou psicológica do agente" (p.43). Novamente, o sociólogo chama a atenção para as duas faces de um mesmo fenômeno, que compõem a já mencionada "cultura do risco" na Modernidade.

Sem a segurança, faz-se imprescindível o exercício da "criatividade" para "agir ou

5 Para evitar repetição desnecessária, uma vez que trabalharemos apenas com esta obra do autor, a partir de agora não mais indicaremos o ano quando mencionarmos seu nome, senão após menção a outro autor. 
pensar de maneira inovadora" (p. 44) ao encarar desafios, e, assim, recapacitar-se. A recapacitação pode reclamar uma mudança no "estilo de vida" do indivíduo, ou seja, em suas "práticas rotinizadas, as rotinas incorporadas em hábitos de vestir, comer, modos de agir e lugares preferidos de encontrar os outros" (p. 80). Segundo Giddens, tanto as pequenas quanto as grandes escolhas "são decisões não só sobre como agir mas também sobre quem ser" (id.; ibid.). E, nesse sentido, postula o autor, "a própria confiança, por sua natureza, é em certo sentido criativa, porque envolve um compromisso que é um 'salto no escuro', um oferecer-se como refém para o acaso, que implica estar-se preparado para abraçar novas experiências." (p.44).

Por outro lado, das dificuldades em recapacitar-se, pode aflorar no indivíduo a "ansiedade existencial", um descompasso entre aspirações e possibilidades reais que fazem hesitar a própria noção de sua existência no mundo. As questões existenciais que surgem nos expõem à terrível ideia de finitude, do que impulsiona a "urgência que se faz sentida como a necessidade de lançar-nos no que a vida tem para oferecer antes que o tempo - para o indivíduo- 'se esgote"' (2002, p. 52).

A “auto-identidade", para Giddens, "não é algo simplesmente apresentado, mas algo que deve ser criado e sustentado rotineiramente nas atividades reflexivas do indivíduo" (p. 54). Portanto, todas as decisões refletem diretamente não apenas no modo como o indivíduo reage, mas também no modo como ele se percebe, se pensa, como se sente no mundo, e é por isso a "auto-identidade" para o autor é um processo constante, um "projeto reflexivo". As questões que nos colocamos, o estilo de vida que assumimos para os planos que projetamos (p. 79), a forma como construímos nossa narrativa, para nós mesmos e para os outros (p. 75) e como decidimos “'seguir em frente' nos contextos da vida cotidiana” (p. 50), tais questões estruturam esse projeto, esse protótipo sempre a se desenvolver, da "auto-identidade".

Nesse percurso, sentimentos como "medo", "ansiedade", "vulnerabilidade", "vergonha", "culpa" afloram e repercutem nas ações e tomadas de decisão, sobretudo porque "A modernidade confronta o indivíduo com uma complexa variedade de escolhas e ao mesmo tempo oferece pouca ajuda sobre as opções que devem ser selecionadas." (GIDDENS, 2002, p. 79). O desafio de atender a uma multiplicidade de questões todos os dias resulta em conflitos interiores que podem levar, ainda, à "falta de sentido pessoal - a sensação de que a vida não tem nada a oferecer" (id., p.16), e, portanto, à inação.

O imperativo de estruturar "narrativas biográficas coerentes" (p.12), de interpretar-se e reinventar-se faz-se sentir no continuum do cotidiano: "A reflexividade do eu é contínua, e tudo penetra", diz Giddens (p. 75). Todavia, é diante de situações limites que o indivíduo testa a força dessas representações que tem de si mesmo.

A partir dessas considerações teóricas iniciais, e de alguns termos que integram o "vocabulário conceitual" (p. 9) proposto por Anthony Giddens, passaremos a analisar a protagonista do conto, Eveline, a fim de buscar esclarecer o conflito por ela vivenciado, em uma situação aparentemente "limite". Quando for necessário, outros elementos discutidos pelo sociólogo serão igualmente utilizados e devidamente comentados. 


\section{DUBLINERS, SEU TEMPO, SEU CONTEXTO. “EVELINE”, SEUS TEMPOS, SEU}

\section{ESPAÇO.}

A obra Dubliners, do irlandês James Joyce (1882 -1941), publicada pela primeira vez em 1914, é constituída por quinze contos, ambientados em um mesmo cenário, a cidade de Dublin. Segundo o crítico Terrence Brown (1992), na "Introdução" da edição utilizada, além do espaço, os contos também compartilhariam do mesmo tempo, o início do século XX, quando a cidade vivia um momento de declínio (p. xvii). O olhar clínico de Joyce sobre a miséria humana circulante nesse espaço urbano faz de Dubliners um retrato dessa sociedade, composta sobretudo por pessoas em situação economicamente frágil (p. xx- xxiii), que desfilam em roupagens fictícias.

O realismo descritivo de Joyce, não apenas na apresentação do espaço, mas, especialmente, na representação da condição humana neste espaço, indiciaria uma relação umbilical com a cidade nativa do autor. Segundo Brown (1992):

Este texto, como toda a obra de Joyce, contém matéria autobiográfica e é enraizado em uma apreensão intensamente cuidadosa do detalhe da vida de Dublin que Joyce observou em seu entorno até chegar à fase adulta. ${ }^{6}$ (p. xiii).

Destarte, o escritor teria colhido a matéria-prima para tais narrativas das camadas de vida ao seu redor. De fato, nas notas da edição utilizada para este trabalho, muitas são as referências a eventos e personagens históricos e curiosidades sobre a Dublin da época, fornecidas por vezes como essenciais para uma compreensão mais profunda dos contos.

Se Dubliners está para as mudanças no cenário da cidade de Dublin, à semelhança do fenômeno moderno analisado por Giddens, Eveline está para o indivíduo cuja auto-identidade desenvolve-se nesse cenário mutável. Tendo em vista essas relações, passemos a comentários estruturais do texto, a fim de prosseguir, posteriormente, à análise da protagonista.

Narrado em terceira pessoa, o conto "Eveline" apresenta uma situação, que se limita temporalmente ao momento de uma decisão, em que uma jovem de dezenove anos decide seu destino: ou ficar em casa, a trabalhar e a viver para o pai e os irmãos, visto que a mãe morrera, ou abandonar tudo e fugir para outro país, com um marinheiro que lhe promete uma vida diferente e maravilhosa. Há apenas dois marcadores do tempo cronológico, "assistindo ao entardecer invadir a avenida"7 (JOYCE, p.29; grifo nosso), no primeiro parágrafo, e, posteriormente, a modulação para "O entardecer aprofundou-se na avenida." (id., p. 32, grifo nosso $)^{8}$. Neste curto arco temporal, de transição do dia para a noite ${ }^{9}$, entre o entardecer invadir e tomar por completo a avenida, instaurando a escuridão, a narrativa assume

\footnotetext{
6 "This text, like all of Joyce's work, contains autobiographical matter and is rooted in an intensely accurate apprehension of the detail of the Dublin life Joyce had observed all about him as he grew to adulthood.".

7 "watching the evening invade the avenue."

8 "The evening deepened in the avenue.".

9 Nesse sentido, o tempo assume igualmente um teor simbólico na narrativa: a transição do dia para a noite está para o deslocamento espacial da viagem e a transição entre dois momentos da vida de Eveline.
} 
outro ritmo, alocando-se no espaço psicológico de Eveline, a partir do qual pensamentos e recordações são explicitados.

Assim, outro plano instaura-se no percurso diegético, não uma ação factual, mas o desenvolvimento de uma ponderação, um processo íntimo de uma identidade em conflito. Interiormente há uma efervescência de pensamentos e sensações, em um descompasso entre experiência externa e atividade psíquica. Desbordando os limites de tempo e espaço, a narrativa absorve o fluxo dos pensamentos da personagem. Não se movendo fisicamente, Eveline é toda fluxo interior. Dentro de si, dúvidas colidem na relação entre passado e possível futuro. O presente é o tempo suspenso, a hesitação. No plano da narrativa, os espaços externos são simbólicos, a janela da casa e o porto da cidade, e os internos opõem tempo passado, o mundo que bem conhece, e tempo futuro, o mundo que projeta em sonho. Nesse quadro, já se verifica a manifestação de um estado de ansiedade, no conceito kierkegaardiano, de que Giddens (2002) se apropria, como derivante "da capacidade - e, de fato, necessidade - do indivíduo de pensar para frente, de antecipar possibilidades futuras em relação à ação presente." (p. 50).

A simbologia do primeiro espaço externo corrobora esse impasse, fruto da ansiedade. A janela simboliza a dicotomia de acesso ao exterior e, concomitantemente, exposição do interior. Uma janela, logo, é uma abertura, que representa tanto uma possibilidade quanto um risco. Uma janela de uma casa torna-se ainda mais expressiva, visto que a casa é um lugar de intimidade e permanência. Destarte, "janela da casa” carrega em si algo de paradoxal, a casa, como casulo protetor, apresenta uma fissura. A janela da casa é o "muro" em cima do qual a personagem Eveline encontra-se. E dele não sai propriamente, visto que a transição do lugar físico é suspensa em termos de narração. Abruptamente, de um parágrafo para outro, com o espaço de uma linha em branco, a protagonista surge em outro lugar: o porto, "na estação de North Wall"10.

Desde aí se percebe que o conto é tramado por oposições e por vezes duplicações, instaurando uma atmosfera de ambiguidades, incertezas. O porto é algo como uma janela. Seria a janela da cidade, a saída bem como a entrada. Logo, temos, nesses dois e únicos espaços físicos em que ocorre a cena factual, a duplicação do mesmo símbolo, ou melhor, uma ampliação deste. Da casa, espaço privado, ao porto, espaço público, oscilação entre o familiar e o estrangeiro. Ambos os espaços representam o "risco" de que Giddens trata, e são, ambos, espaços limiares. Entretanto, o espaço interior segue regendo o tempo e o tom da narrativa.

Passando a questões estilísticas da construção diegética, um dos fatores que acentua o realismo do conto, e nos faz aproximar dessa "quase pessoa", é a técnica narrativa utilizada por Joyce e que se consagrou como uma marca de estilo dos romancistas modernos. Ao percorrer a trajetória da representação da realidade em narrativas ocidentais, Erich Auerbach (2004), em sua monumental obra Mimesis, parte das epopeias homéricas e de textos evangélicos até aportar nos romances modernos. Destes, detém-se primeiramente em Virgínia Woolf e posteriormente em Proust, analisando-lhes a técnica que modificou substancial-

10 "in the station at the North Wall". À exceção do porto em questão (cujo nome é o mesmo do da cidade de Dublin), em "Eveline", a Dublin real não se faz presente como espaço significativo, mas as diversas alusões indiciam mudanças que a cidade realmente sofreu, como veremos posteriormente. 
mente a forma de narrar: o "fluxo de consciência"11. O autor afirma que, embora não seja de todo nova, essa técnica passa a ser utilizada neste momento com outra intenção, a "de fazer com que se confunda, ou até que desapareça totalmente, a impressão de uma realidade objetiva" (p.482). A isso deve-se um fenômeno, aí sim novo, da sensação de que o próprio criador das personagens hesita sobre o que lhes está acontecendo. Sob esse prisma, poderíamos entender que o "estatuto da dúvida", que, para Giddens (2002), impera sobre os indivíduos modernos, teria tomado inclusive a figura do autor, para quem, segundo Auerbach (2004), "a verdade acerca da sua personagem não lhe fosse mais bem conhecida do que às próprias personagens ou ao leitor" (p.482).

Outra das expressivas mudanças características dos romances modernos, segundo Auerbach (2004), é a escolha por eventos quotidianos isolados, por vezes rotineiros, em detrimento de grandes feitos - como nas epopeias- ou de grandes acontecimentos na vida individual de uma personagem- como nos romances tradicionais. Em Woolf, Proust, Joyce, retratam-se momentos isolados, mas que, todavia, representam uma "visão sintética do mundo", (p. 495). No conto em questão, "Eveline”, igualmente, não há um grande acontecimento a ser narrado. Mas essa falta de conteúdo é justamente a vida da protagonista, que, aliás, sequer conta sobre si mesma, não constrói, nas palavras de Giddens (2002), sua "autobiografia", "uma auto-história interpretada." (p. 75).

O fato de ser narrado por outrem, além de apontar para uma incapacidade de expressão, ainda se configura como outro elemento estilístico próprio do romance moderno. $\mathrm{O}$ indivíduo em crise é visitado em seu íntimo e toda a atividade mental e sentimental pode ser exposta em palavras. Postula Auerbach (2004) que o próprio "ritmo sempre crescente", bem como o "violento ritmo das modificações" e as "crises de adaptação" (id., ibid.) da vida real(o que, aliás, está em consonância com a certeira frase de Giddens [2002], "O mundo moderno é um 'mundo em disparada' [p. 22]) contaminam a literatura via técnica do "fluxo de consciência", através da qual a figura do narrador atingiu "os limites da sua liberdade no tempo e no espaço que lhe são impostos por seu instrumento, a linguagem” (p.492).

Ao adentrar o íntimo da personagem e romper as barreiras de tempo e espaço do mundo real, regendo-se pelo tempo da consciência, o romancista cria uma nova forma de organizar a narrativa, alterando o efeito da obra sobre o leitor. Ainda, ao comentar a obra máxima de Joyce, o romance Ulisses, Auerbach (2004) ressalta "a sensação de fim de mundo" e "de desesperança", "algo de confuso ou de velado, algo que é inimigo da realidade que representam [esses romances modernos]" (p.496). É como se o próprio narrador estivesse se perguntando o que há para narrar? .Tal fenômeno se assemelha a uma das características do "projeto reflexivo do eu", que Giddens (2002) diagnostica: "Começando com uma série de perguntas feitas conscientemente, o indivíduo se acostuma a perguntar 'como posso usar este momento para mudar?'” (p. 75). Eis o ponto nevrálgico do conto em questão. Nada há para ser narrado e há, no fim, a desesperança, a ruptura da possibilidade de um grande evento, o qual, antes, motivava as grandes narrativas clássicas.

O fim do conto, que confirma a incapacidade de ação da protagonista, reforça esse anticlímax, a quebra da expectativa de que Eveline optaria por um mundo novo. Embora seja uma short story, não há sequer um núcleo de ação propriamente dita, há o pensamento, a 
confusão emocional e psíquica, a qual, por outro lado, passamos a conhecer de forma muito aguda. É a sua não-narrativa que nos é contada. Eveline torna-se, ao fim, um ser paralisado frente à dinamicidade da vida moderna, que a Dublin real, modelo para a fictícia, como já comentado, sentiu nas grandes mudanças que promoveram declínios em vários setores da cidade.

A personagem em questão é construída em cima de sua própria hesitação. A fim de aprofundarmos esse ponto, passemos à análise textual propriamente da protagonista Eveline, conjugada mais intimamente com conceitos do sociólogo Anthony Giddens.

\section{EVELINE CONSTRUÍDA NA REFLEXIVIDADE.}

O que sabemos inicialmente de Eveline? Pontualmente, onde ela está fisicamente "sentou-se à janela" ${ }^{12}$, logo, dentro de casa; como se sente, "Ela estava cansada"13, embora desconheçamos o motivo desse cansaço; e o que está por lhe acontecer, "Agora ela está prestes a ir embora como os outros, deixar seu lar." ${ }^{14}$. Como os "outros", ela está na iminência de ir embora, mas "os outros" são tanto a mãe, que morrera, quanto a família de vizinhos que retornara à Inglaterra. Já nesse primeiro momento a ambiguidade recai sobre a locução "ir embora": morrer, como a mãe, ou mudar-se, como a família de vizinhos. De qualquer forma, ambos os sentidos apontam para o desafio de quebrar um condicionamento, lançar-se ao desconhecido.

"Deixar seu lar"15 assume ainda outra conotação, que se completa no parágrafo posterior, o qual inicia justamente com o eco da palavra "Lar" ${ }^{16}$, porém com exclamação. Uma pontuação subjetiva, logo, um pensamento, em um traço evidente de monólogo interior, quem sabe um questionamento da jovem sobre o que seria realmente este "lar". E então o parágrafo nos apresenta alguns lances do passado que ela viveu dentro dessa casa. Seu olhar para os objetos, dos quais "tirou o pó uma vez por semana por tantos anos" ${ }^{17}$, marca o primeiro momento em que vislumbra uma separação, a ruptura desses longos anos. A repetição de um ato, no caso o de limpar tais objetos liga-se, na visão de Giddens (2002), à sensação de "segurança ontológica": Eveline encontra sua razão de existir na relação com esses "objetos familiares" ${ }^{18}$, os quais, embora lhe fossem ordinários, passam a assumir um papel importante, visto que representam "tantos anos", boa parte de sua vida e, mais do que isso, parecem lhe falar sobre si mesma.

Detenhamo-nos neste segundo parágrafo, a fim de explicitar-lhe a expressiva construção. Inicia-se com "Algumas pessoas passaram"19. A ideia de deslocamento, em "passaram", em um primeiro momento, refere-se a uma constatação visual de Eveline, naquele tempo es-

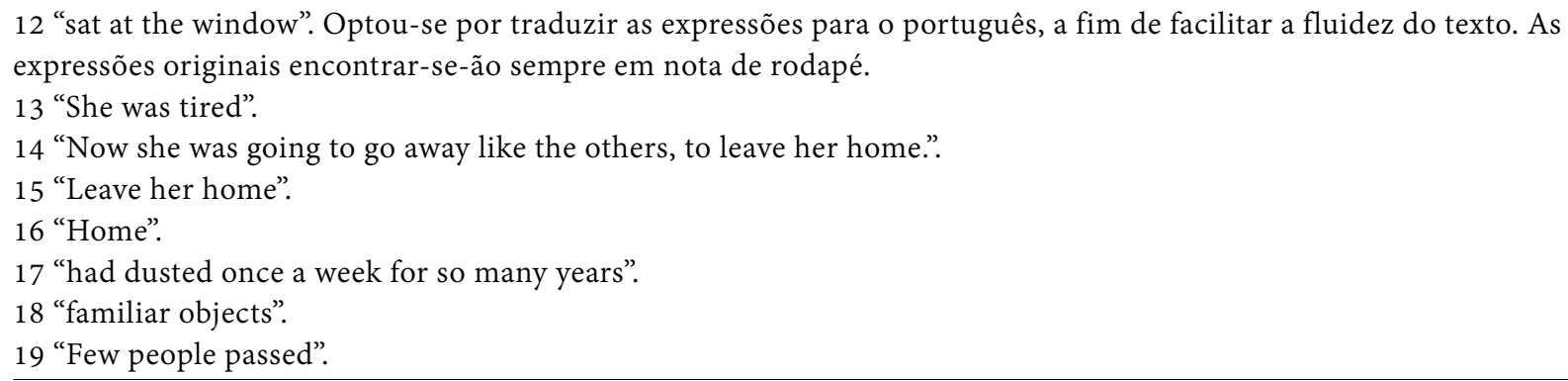


pecífico do anoitecer, mas que também poderia aludir às pessoas que “morreram”. Essa ambiguidade entre partir e morrer, já presente anteriormente, mostra-se como um dos grandes signos do conto. Este parágrafo introduz pessoas do convívio da protagonista: que passaram por sua vida, ou que morreram. O primeiro período, "O homem sai da última casa" ${ }^{20}$ é claramente de uma constatação visual. Eveline, da janela, vê que ele "passou no caminho até sua casa" ${ }^{21}$. Estamos no tempo e espaço exteriores; todavia, dessa observação dá-se o ponto de partida para uma imersão na memória: "Uma vez" ${ }^{22}$ abre o período seguinte e desloca o tempo da narração para um passado mais distante, dando início ao fluxo de consciência. "Então um homem de Belfast" 23 (quarto período) modificou o espaço da rua: comprou o campo, onde "As crianças [...] costumavam brincar" 24 (novo período) e construiu novas casas, bem diferentes das outras, inaugurando um novo momento da vizinhança ${ }^{25}$.

Da sequência percebe-se uma gradação no início de cada período, do mais geral, "Algumas pessoas" 26 , para o particular: "Ernest" (novo período), é a primeira personagem nomeada individualmente, antes há apenas pronomes, sobrenomes, topônimos. Na sequência, retorna-se ao tratamento geral, "Seu pai", ${ }^{27}$ expressão que se repete posteriormente, em uma interessante estrutura sintática, duas orações ligadas por ponto e vírgula e pela expressão "e além disso" ${ }^{28}$ : "seu pai não era tão ruim então / sua mãe era viva." 29 . A morte da mãe e a ruindade do pai colocam-se em par de igualdade, a negação da maldade dele coincidiria com a negação da morte da mãe, logo, implicitamente poder-se-ia considerar que após a morte da mãe o pai tornou-se mais mau. Maldade que, voltando ao primeiro período, indicia-se pelo seu hábito de espantar as crianças com sua bengala. A oração que opõe o pai e a mãe de Eveline encerra essa primeira memória, com "Isso fora há muito tempo" ${ }^{30}$, parecendo marcar uma distância subjetiva, mais forte do que o primeiro marcador temporal "Uma vez", inclusive porque abre um elenco de mudanças: ela e seus irmãos haviam crescido, e, mais uma vez, a morte da mãe é mencionada, mas agora em frase assertiva, "sua mãe estava morta" 31 .

Segue-se novo período tratando das pessoas que se foram: Tizzie Dunn, que "também estava morta" 32 , e a família Waters, que se mudou para a Inglaterra. O penúltimo período, "Tudo muda" 33 , soa como um complemento opositivo do primeiro, "Algumas pessoas passaram”, em um contraste entre o tempo cronológico, durante o qual "algumas" pessoas

20 "The man out of the last house".

21 "passed on his way home".

22 "One time".

23 "Then a man from Belfast".

24 "The children [...] used to play".

25 Segundo a nota de explicação, esse "homem" vindo de outra cidade representaria, ainda, um estereótipo de uma "agressividade comercial e filistina presunção" (JOYCE, p.254) das pessoas vindas de Belfast que realmente provocaram mudanças na Dublin real.

26 "Few people".

27 "Her father".

28 "and besides".

29 "her father was not so bad then/ her mother was alive."

30 That was a long time ago".

31 "her mother was dead".

32 "Tizzie Dunn was dead too".

33 "Everything changes". 
passaram fisicamente ali, e a sensação presente de que "tudo" é passível de mudança, haja vista as pessoas que passaram pela sua vida. O verbo "mudar", tanto no sentido de mudança do estado geral das coisas como de deslocamento físico, novamente estabelece ambiguidade, tal como a assinalada no início, na relação entre os verbos "mudaram" e "passaram" do primeiro parágrafo do conto - à diferença de que "mudar" está agora no tempo presente ${ }^{34}$, indiciando um pensamento válido para a situação atual, que soa como uma máxima se sabedoria.

Neste trecho, encontramos parte do passado da personagem e o signo da mudança marcando-o e assinalando um possível passo futuro. É claramente o que Giddens chama de "reflexividade", a ação de confrontar e pesar os fatos a fim de tomar uma decisão, que no caso de Eveline desponta como uma grande transformação. Nesse sentido, Giddens afirma que "Transições nas vidas dos indivíduos sempre demandaram reorganização psíquica, algo que era frequentemente ritualizado nas culturas tradicionais na forma de ritos de passagem." (p.37). O conto nos apresenta o momento antes do "rito de passagem" da jovem para a vida adulta, o qual, todavia, deve ser pensado, organizado e executado apenas por ela mesma.

A ponderação que realiza, "Ela tentou medir cada lado da questão"35, aponta para esse exercício de "reorganização psíquica", que, contudo, não se completa e, portanto, não impulsiona uma ação posterior. A casa afigura-se-lhe como o "casulo protetor" que Giddens afirma ser essencial para o desenvolvimento da "confiança". Mas esse casulo significa para Eveline apenas elementos de sobrevivência física, "abrigo e alimento" ${ }^{36}$, logo, casa, não realmente "lar", e, por outro lado, as pessoas, que poderiam ser-lhe a garantia do conforto emocional, e da "segurança ontológica", tornam-se, em sua ponderação, os "outros"37, que, caso viessem a saber de sua fuga com o namorado, lhe condenariam pela ingenuidade, viriam a "Dizer que ela é uma tola" ${ }^{38}$. Neste trecho, deixa-se entrever a preocupação com a reação dos outros, que reforça sua insegurança. O peso da estrutura social cai-se-lhe como um desafio para sua "emancipação". Segundo Giddens, "atitudes de confiança em relação a situações, pessoas, [...] estão diretamente ligadas à segurança psicológica dos indivíduos e grupos" (p.25). Sua decisão, que, aliás, é só sua, é, contudo, contaminada pela insegurança que sente na ausência de apoio alheio e na censura de que imagina tornar-se alvo.

Tais elementos, submetidos a um contraste na mente de Eveline, nos expõem a insegurança de seu "eu". Além disso, a promessa de seu namorado, um marinheiro, é a de um mundo maior, cuja passagem, na imagem do mar, que eles deverão atravessar, impõe-se como o desconhecido assustador e custa-lhe toda a "confiança". Frente a isso, a sensação da jovem assemelhar-se-ia com a "ansiedade", na concepção de Giddens. Para o autor, a "ansiedade", diferentemente do "medo", é um desconforto frente ao que desconhecemos,

34 Em relação a tempos e modo verbais, o conto apresenta-se praticamente construído com pretéritos e condicionais passados, que indiciariam desde o início que Eveline abortaria seu sonho antes mesmo de nele embarcar. Por outro lado, a assertiva "Everything changes", no presente, ecoa como uma certeza intemporal, abre a possibilidade de que ela venha a aceitar o desafio. Como já mencionado, o conto é rico em artifícios que conduzem à ambiguidade, reforçando o efeito de tensão e suspense que se mantém até o final.

35 "She tried to weigh each side of the question".

36 "shelter and food".

37 "others".

38 "Say she was a fool". 
enquanto o medo direciona-se a um objeto específico e conhecido (p. 48). Assim, Eveline prova "ansiedade" na possibilidade de um futuro distante do "lar", em um "país distante e desconhecido" 39 e "medo" pela ideia de ficar, na sua realidade triste e sem expectativas, "medo" do que conhece muito bem, de ter o mesmo destino de sua mãe. Se partisse, "Ela não seria tratada como sua mãe o tinha sido." ${ }^{40}$, herança que se reflete no seu presente, resumido em "trabalho difícil - uma vida difícil" ${ }^{41}$. Eis que, neste momento, acessamos o motivo do cansaço de Eveline: a rigidez e imposição do pai, que lhe exige trabalhar fora e manter a casa e os irmãos pequenos. Sem a coragem de modificar o quadro, caiu no que Giddens determina como uma "espécie de apatia resignada" (p. 20), até um ponto em que essa rotina "começou a cansá-la de maneira indizível" 42 .

$\mathrm{Na}$ família, ela era a irmã entre dois irmãos mais velhos, um já morto, Ernest, e outro, Harry, que viajava a trabalho, e dois menores, que ela deveria cuidar. Literalmente no meio entre os irmãos, com a ausência dos mais velhos, sentia que "não tinha ninguém para protegê-la" 43 , e , sendo, portanto a mais velha na ocasião, "Ela teve de trabalhar pesado para manter a casa unida" ${ }^{44}$. A casa, sob essa ótica era uma prisão, cujo pilar central, entretanto, encontrava-se nela, era ela a sustentar a própria estrutura que lhe prendia. Contudo, mesmo sendo este um lugar que lhe exige sacrifício, Eveline, ao cogitar ir embora, passa a vê-lo sob aspectos positivos: "mas, agora que ela está prestes a partir, não lhe parece uma vida totalmente indesejada." 45 . A fuga com o namorado significa uma decisão de "emancipação", uma opção por um novo "estilo de vida", que quebre a cadeia natural que lhe arrasta passivamente. Segundo Giddens, a escolha pelo "estilo de vida", que nos coloca em relação a certas instituições e situações em detrimento de outras, a "realização" de uma pessoa "é em parte um fenômeno moral" (p.80),e a faz repensar sua responsabilidade consigo e com os demais. Nesse sentido, o peso da família de Eveline impõe-se claramente, não como um laço afetivo, mas como um dever. Ela está diante de uma escolha entre ela mesma e o início de uma relação pessoal arriscada e incerta, que lhe exige entrega, logo, "confiança", e a manutenção de uma zona de conforto, por significar a manutenção do previsível, a proteção de "novos riscos".

Frank, o marinheiro, representa essa possibilidade de uma "outra vida" 46 . Sua imagem contrasta-se com a do pai: enquanto este lhe oprime, Frank apresenta-se-lhe "muito gentil, viril, de coração aberto" ${ }^{47}$, alguém que lhe conta histórias de "países distantes" 48 e reparte suas experiências com ela. Nesse sentido, expressivo o significado do nome do jovem, "franco", que poderia apontar tanto para uma característica positiva quanto para uma ironia, visto que a figura de marinheiro geralmente está associada à de aventureiro, em sentido pejorativo, e inventor de histórias. A transição da figura masculina dominante, do pai para

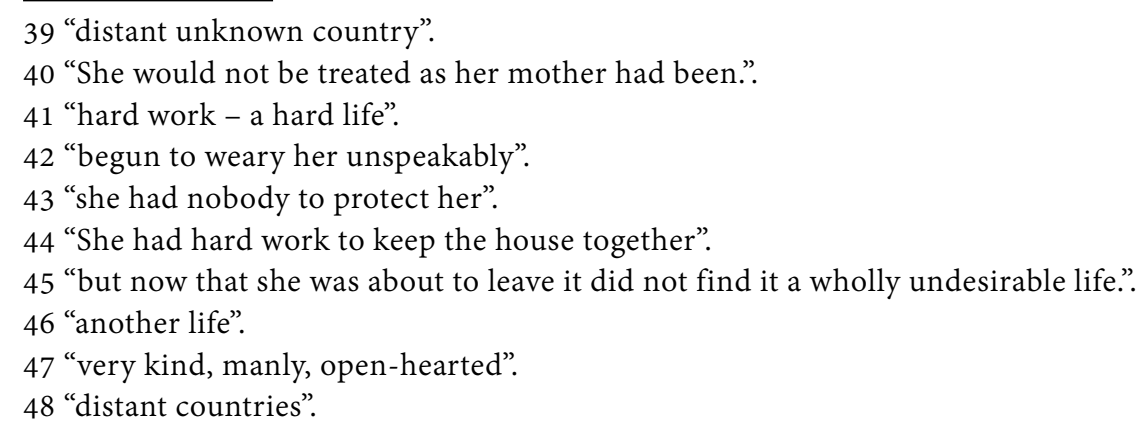


o marido, mostra-se também como um conflito, em última análise da própria transição do passado ao futuro. O pai não aceita o namoro da filha e lhe adverte, "Eu conheço esses jovens marinheiros" ${ }^{49}$, palavras nas quais também não fica claro serem de preocupação ou apenas de veto. E para o contraste acentuar-se ainda mais, vem-lhe na memória uma cena do pai justamente como contador de histórias, mas, que, todavia, era uma "história de fantasmas" ${ }^{\prime 2}$.

Nessa comparação podemos interpretar o que cada homem lhe simboliza: o pai representaria a segurança da tradição, que positivamente sustentaria o "casulo protetor" e negativamente provocaria o sentimento de "isolamento existencial", ou seja, "a separação dos recursos morais necessários para viver uma existência plena e satisfatória” (p. 16); por sua vez, Frank representaria a "dúvida", o "risco", que positivamente seria a possibilidade do exercício da "emancipação", em uma decisão de "autenticidade", o que, para Giddens, é referência para a "auto-realização", e que neste caso implicaria numa mudança de "estilo de vida", mais feliz; por outro lado, Frank poderia não atender a suas expectativas, o que resultaria no "luto", na "raiva", na "amargura" de uma escolha mal feita. Independentemente de sua resolução, a situação exige de Eveline a "coragem moral" e a "persistência" para continuar, seja em uma nova vida, seja na manutenção da atual. Nessa esteira, poderíamos entender o conto como uma alegoria da busca de um "novo sentido do eu".

Retomando a sequência do conto, a já mencionada expressão, "O entardecer aprofundou-se na avenida" ${ }^{1}$, marca o distanciamento temporal em relação ao primeiro parágrafo, quando ela estava "assistindo ao entardecer invadir a avenida" 52 e, entre esses dois momentos, há a sensação de que "Seu tempo estava esgotando-se" 53 , o tempo passava, ela seguia à janela, imóvel. Novas memórias lhe vêm: infância, quando a mãe era viva, e o pai "podia ser legal" 54 , e o dia de sua morte, ressuscitado pela memória olfativa e auditiva. O cheiro que sente, "odor do cretone empoeirado" 55 , e a música que ouve, "um órgão de rua tocando" parecem recriar a mesma atmosfera do dia da morte da mãe. E com isso, retorna-lhe à mente a promessa, a obrigação para com a família.

A lembrança da mãe, contudo, surge como o fator aparentemente decisivo para Eveline, cuja vida "de sacrifícios comuns encerrando-se em uma loucura final" ${ }^{57}$ lhe causa algo como uma paralisia, um "impulso de terror" ${ }^{8}$, o qual instantaneamente lhe impele a partir, "Escapar! Ela deve escapar!”"59, e recoloca o marinheiro como a saída, "Frank a salvaria"60, a segurança, e, assim, deposita nele a "confiança", vê nele por um momento o "casulo pro-

\footnotetext{
49 "I know these sailor chaps".

50 "ghost story".

51 "The evening deepened in the avenue.".

52 "watching the evening invade the avenue.".

53 "Her time was running out".

54 "could be nice".

55 "odour of dusty cretone".

56 "a street organ playing".

57 vida "of commomplace sacrifices closing in final craziness".

58 "impulse of terror".

59 "Escape! She must escape!".

60 "Frank would save her".
} 
tetor", o lar, que não é apenas mais "alimento e abrigo" ${ }^{61}$, mas "talvez amor, também"62. A mãe é a lembrança do horror, de um futuro de loucura. Sem a figura materna, e a figura paterna colocando-se como censor, à protagonista "falta o apoio psicológico e o sentido de segurança oferecidos em ambientes mais tradicionais" (GIDDENS, 2002, p. 38).

Tudo até aqui fora reflexo de sua psique, e a cena ocorre fisicamente no mesmo ponto da casa, "à janela", um lugar que ao mesmo tempo é refúgio e abertura para o exterior. A decisão final, por outro lado, dá-se no porto, um ponto de partida - ou de adeus. Todavia, a configuração da cena parece reproduzir a inicial, em paralelismo sintático e semântico, "Ela sentou-se à janela" ${ }^{63}$ versus "Ela ficou entre a multidão cambaleante" 64 . Antes ela estava imóvel à janela, marca do espaço familiar, do casulo, ao passo que no porto ela estava imóvel no meio da multidão que se movia, de gente que partia, uma onda que lhe deslocava à força.

Assustada, Eveline parece desconhecer Frank, estar-lhe indiferente "ela sabia que ele estava lhe falando, insistindo em algo sobre a passagem, repetidamente" ${ }^{65}$. Em reação a essa confusão, volta-se a um hábito, que lhe restituiria a "confiança": "ela rezou para que Deus a direcionasse" ${ }^{66}$. Para Giddens (2002), a crença na "razão providencial" exerce um poder de conforto nas pessoas, "leva os seres humanos a uma existência mais segura e satisfatória" (p. 33). Eveline começa a rezar em uma atitude quase mecânica, sua oração parece fazer ecoar a frase sem sentido que sua mãe repetira antes de expirar "Derevaun Seraun! Derevaun Seraun!". "Na silenciosa e fervorosa oração" ${ }^{67}$, toda a ponderação racional que fizera até então naufraga na inconsciência, na "ansiedade", e ela recua, retorna às lembranças, ao casulo asfixiante e busca algo que lhe tire o peso da escolha, que decida por ela. A "dúvida", o "medo" do "risco" que Frank e o mar e a nova vida que lhe era ainda vaga desproveram-na de "sentido pessoal" (GIDDENS, 2002, p. 16), que, ao fim, simplesmente "Suas mãos agarraram o ferroem frenesi" ${ }^{68}$, e ela lançou ao mar, ao destino de um futuro fantasma, "um choro de angústia"69. Essa personagem esvazia-se então de identidade e resta como um "animal desamparado"70, cuja face não transparece senão a vagueza, a falta de sentido. O animal, o ser irracional, indefeso, pois não entende os perigos. Animal, desprovido de "consciência prática", que Giddens afirma ser "a âncora cognitiva e emocional da sensação de segurança ontológica” (p. 40). A imagem ainda parece colocá-la em uma jaula, pois ela fica trancada na barra de ferro, um obstáculo que materializa sua fraqueza, além de se afigurar a uma âncora. Despreparada para o que seria seu "rito de passagem", decide por não decidir.

Nessa última cena, que se passa no porto, importantes palavras que designam emoções pontuais são utilizadas, dando forma a sentimentos (que até então eram mesclados em sensações confusas) e que, ao final, intensificam-se e modificam as feições de Eveline, até

61 "food and shelter".

62 "perhaps love, too".

63 "She sat at the window".

64 "She stood among the swaying crowd".

65 "she knew that he was speaking to her, saying something about the passage over and over again".

66 "she prayed to God to direct her".

67 "in silent fervent prayer".

68 "Her hands clutched the iron in frenzy".

69 "a cry of anguish".

70 "helpless animal". 
serem nominados: "um labirinto de aflição"71, "sua aflição suscitou-lhe uma náusea"72, "um choro de angústia"73, "sem sinal de amor ou adeus ou reconhecimento"74. Frank era-lhe, afinal, um estranho. Uma vez que "Identificação e projeção são os principais meios através dos quais possíveis espirais de ansiedade e hostilidade são evitadas" (GIDDENS, 2002, p. 48), para libertar-se do horror, ela deve deixá-lo partir só.

Giddens afirma que "Os indivíduos tendem a se recapacitar em maior profundidade quando se tratam de transições importantes em suas vidas ou quando precisam tomar decisões sérias" (p.14). Eveline, sob esta ótica, teve de se recapacitar após a morte da mãe, pois passou a assumir seu papel de responsabilidade pelo lar. Essa mudança lhe ocasionou um "isolamento existencial". Por outro lado, quando teve de decidir por outro "estilo de vida", "num ambiente exterior cheio de mudanças", no caso, o porto, sentiu-se "obsessivamente preocupada com o medo dos riscos possíveis para sua existência, e paralisada em termos de ação prática" (GIDDENS, 2002, p.55). O conto que leva seu nome é, sob esta ótica, o relato de sua incapacidade de decisão, sua paralisia frente a um mundo de possibilidades que se lhe abria, mas no qual ela, hesitante e inerte, não teve coragem para embarcar.

Para o sociólogo, "Ser ontologicamente seguro é ter, no nível do inconsciente e da consciência prática, 'respostas' para questões existenciais fundamentais que toda vida humana de certa maneira coloca" (p. 49). Em Eveline, não ocorre o "salto de fé" (p.11) que Giddens entende como o grande passo de aceitação do risco e marco de início de uma mudança. Agarrada a um ferro, a um item concreto e exterior, ela simbolicamente diz a Frank que não pode partir, porque está sustentando o que lhe impede o movimento. O ferro é ela mesma, a âncora de uma auto-identidade naufragada.

\section{CONCLUSÃO}

Quando avalia as condições do indivíduo frente às constantes demandas que o mundo moderno lhe impõe, Anthony Giddens postula que a grande pergunta à qual todos devemos responder a cada escolha é "Como devo viver?". O coração do conto de Joyce bate justamente nesse ponto, dolente, que Eveline sente. A resposta lhe guiaria para frente, para o risco, o mar, a dúvida, ou lhe faria ancorar no dogma, na tradição, na anulação. Enquanto pondera, o que experimenta é a "ansiedade" que esta decisão lhe provoca. O olhar taxativo dos "outros", vizinhos, patrões, conhecidos, agem como um questionamento sobre sua capacidade e coragem em assumir um novo "estilo de vida". A família, tanto os vivos, pai e irmãos, quanto os mortos, mãe e irmão preferido, por sua vez, pesa como uma âncora sobre seus desejos. Incapaz de se decidir, não toma parte na autoria de sua própria vida. Não compõe, como diz Giddens, a "sua biografia", a história de sua vida, pois apenas segue uma sequência passivamente. Sob este ponto, especificamente, a narração em terceira pessoa com foco narrativo na personagem reforça ainda mais a falta de autonomia sobre si mesma.

\footnotetext{
71 "a maze of distress".

72 "her distress awoke a nausea".

73 "a cry of anguish".

74 "no sign of love or farewell or recognition".
} 
Como vimos, o conto "Eveline" é tramado por oposições. Há dois espaços, interior e exterior, e este ainda desdobra-se em dois; dois tempos, passado e futuro do pretérito, e, poder-se-ia afirmar, duas Evelines, a que existe em função dos outros e a que sonha ser e se realizar com o namorado. Quase tudo no conto é possibilidade, a mbiguidade e inação. Nada parece ser firme, a não ser o passado que já findou e a casa que parece ter se eternizado no dia da morte de sua mãe. Como um relógio que não mais pendula, fisicamente Eveline não se move, mas interiormente tudo está em movimento e é justamente a ação psicológica que impulsiona a narração e que igualmente configura-se como o peso que ao final lhe faz ancorar em um presente de anulação.

As personagens agem como pessoas, e, embora ficcional, a impressão de sua presença é bastante forte a ponto de nos tocar a pele da sensibilidade - ou da razão. Nessa direção, Eveline seria um bom exemplo, uma bela metáfora da situação que enfrentamos na realidade, da ansiedade e do medo que provamos ao nos testarmos frente ao que é imposto e ao que é ofertado. Quando gozamos da liberdade, ou quando nos permitimos a liberdade, o mar, o mundo que se apresenta grandioso e cheio de possibilidades pode vir a ser o risco da morte ou a total plenitude da vida, do sentido da vida. Podemos nos arriscar em desafios e construir auto-biografias de superação, ou, como Eveline, ficar simplesmente a ver navios a partir.

\section{REFERÊNCIAS BIBLIOGRÁFICAS}

AUERBACH, Erich. Mimesis: a representação da realidade na Literatura Ocidental. São Paulo:

Perspectiva, 2004.

BROW, Terrence. Introduction. In: JOYCE, James. “Eveline”. In: Dubliners. Penguin Books, 1992. pp. vii-xlix.

FORSTER, Edward Morgan. Aspects of the Novel. London: Penguin Books, 1976.

GIDDENS, Anthony. Modernidade e identidade. Rio de Janeiro: Jorge Zahar Ed., 2002.

JOYCE, James. Eveline. In: .Dubliners. London: Penguin Books, 1992. pp. 29-34.

Title: Structure of hesitation: an analysis of the short story "Eveline", by James Joyce, according to concepts of Anthony Giddens. 
